\title{
Sulfur Poisoning and Regeneration Behavior of Perovskite-Based NO Oxidation Catalysts
}

\author{
Merve Kurt $^{1} \cdot$ Zafer Say $^{1} \cdot$ Kerem Emre Ercan $^{1} \cdot$ Evgeny I. Vovk $^{1,2} \cdot$ \\ Chang Hwan $\mathrm{Kim}^{3,4} \cdot$ Emrah Ozensoy ${ }^{1}$
}

Published online: 29 September 2016

(c) Springer Science+Business Media New York 2016

\begin{abstract}
SO}_{x}$ uptake and release properties of $\mathrm{LaMnO}_{3}$, $\mathrm{Pd} / \mathrm{LaMnO}_{3}, \mathrm{LaCoO}_{3}$ and $\mathrm{Pd} / \mathrm{LaCoO}_{3}$ perovskites were investigated via in situ Fourier transform infrared (FTIR) spectroscopy, temperature programmed desorption and $\mathrm{X}$-ray photoelectron spectroscopy. Sulfation of the perovskite leads to the formation of surface sulfite/sulfate and bulk-like sulfate species. Pd addition to $\mathrm{LaMnO}_{3}$ and $\mathrm{LaCoO}_{3}$ significantly increases the sulfur adsorption capacity. $\mathrm{Pd} / \mathrm{LaMnO}_{3}$ sample accumulates significantly more sulfur than $\mathrm{LaMnO}_{3}$; however it can also release a larger fraction of the accumulated $\mathrm{SO}_{x}$ species in a reversible fashion at elevated temperatures in vacuum. This is not the case for Co-based materials, where thermal regeneration of bulk sulfates on poisoned $\mathrm{LaCoO}_{3}$ and $\mathrm{Pd} /$ $\mathrm{LaCoO}_{3}$ is extremely ineffective under similar conditions. However, in the presence of an external reducing agent such as $\mathrm{H}_{2}(\mathrm{~g}), \mathrm{Pd} / \mathrm{LaMnO}_{3}$ requires much lower temperature $(873 \mathrm{~K})$ for complete sulfur regeneration as compared to that of $\mathrm{Pd} / \mathrm{LaCoO}_{3}(973 \mathrm{~K})$. Sequential $\mathrm{CO}$ and $\mathrm{SO}_{x}$ adsorption experiments performed via in situ FTIR indicate that in the presence of carbonyls and/or
\end{abstract}

Emrah Ozensoy

ozensoy@fen.bilkent.edu.tr

1 Department of Chemistry, Bilkent University, 06800 Ankara, Turkey

2 Boreskov Institute of Catalysis, 630090 Novosibirsk, Russian Federation

3 General Motors Global R\&D Chemical Sciences and Materials Systems Lab, 30500, Mound Rd., Warren, MI 48090, USA

4 Present Address: Advanced Catalysts and Emission-control Research Lab, Powertrain Performance Development, R\&D Division, 150, HyundaiYeonguso-ro, Hwaseong-si, Gyeonggi-do 445-706, Korea carbonates, Pd adsorption sites may have a stronger affinity for $\mathrm{SO}_{x}$ as compared to that of the perovskite surface, particularly in the early stages of sulfur poisoning.

Keywords $\mathrm{LaCoO}_{3} \cdot \mathrm{LaMnO}_{3} \cdot \mathrm{Pd} \cdot \mathrm{FTIR} \cdot \mathrm{DeNO}_{x} \cdot \mathrm{LNT}$

\section{Introduction}

Alleviating the air pollution associated with emissions from mobile applications is an important global problem. Particularly, hazardous gases such as $\mathrm{CO}, \mathrm{NO}_{x}, \mathrm{SO}_{x}$ and unburned hydrocarbons have been recently subject to increasingly more stringent emission regulations [1-3]. In order to meet such tough regulations, automobile industry is constantly searching for alternative technologies and novel catalytic materials. Lean burn engines have become very popular in recent years as they offer high fuel efficiencies and lower $\mathrm{CO}_{2}$ emission. $\mathrm{NO}_{x}$ storage and reduction (NSR) catalytic technology is one of the most popular solutions for lean- $\mathrm{NO}_{x}$ aftertreatment applications [4-18]. NO oxidation/reduction ability and resilience against sulfur/phosphorous $[13,15,19,20]$ are among the most vital capabilities that are essential for such $\mathrm{NO}_{x}$ abatement (i.e. DeNO ${ }_{x}$ ) applications. Precious group metals (PGM), particularly Pt, plays an important role in the DeNO ${ }_{x}$ oxidation/reduction pathways. However the use of $\mathrm{Pt}$ is economically unfavorable, as it significantly increases the overall cost of the catalytic $\operatorname{DeNO}_{x}$ system. Thus, search for Pt-free catalytic alternatives that can provide cost-effective and more competitive catalytic technologies has been carried out for a long time.

Along these lines, novel perovskite systems have been suggested as alternatives for catalytic NO oxidation and $\mathrm{NO}_{x}$ storage [21]. Lanthanum-based perovskite catalysts in 
the form of $\mathrm{ABO}_{3}$ such as $\mathrm{LaMnO}_{3}$ and $\mathrm{LaCoO}_{3}$ are promising candidates for $\mathrm{DeNO}_{x}$ applications due to their inherently high oxidation capability, favorable $\mathrm{NO}_{x}$ conversion, low price and relatively simple synthesis procedures [21-24]. Perovskite catalysts, in general, have also been extensively studied in the literature where they have been demonstrated to be effective in catalytic oxidation, pollution abatement, catalytic hydrogenation/hydrogenolysis, photocatalysis, chemical sensors, electrolysis as well as in solid oxide fuel cell applications [25].

However, perovskite-based catalysts suffer from sulfur poisoning due to their basic surface sites $[26,27]$. The interaction between various families of perovskites and $\mathrm{SO}_{x}$ species has been studied extensively in the literature. For instance, the interaction between $\mathrm{LaCoO}_{3}$ and $\mathrm{SO}_{2}$ was reported to yield $\mathrm{La}_{2}\left(\mathrm{SO}_{4}\right)_{3}, \mathrm{La}_{2}\left(\mathrm{SO}_{3}\right)_{3}, \mathrm{La}_{2} \mathrm{O}_{2} \mathrm{SO}_{4}$, as well as $\mathrm{CoO}$ and $\mathrm{Co}_{3} \mathrm{O}_{4}$ species, where the latter species were suggested to form upon the destruction of the perovskite structure [28]. Annealing at higher temperatures was found to facilitate the removal of sulfates/sulfites, however complete regeneration of the $\mathrm{LaCoO}_{3}$ perovskite structure was not feasible. Zhang et al. [29] also observed the destruction of the $\mathrm{LaCoO}_{3}$ perovskite lattice via sulfur poisoning. Partial recovery of the $\mathrm{LaCoO}_{3}$ structure was achieved by exposing the sample to a reducing atmosphere. Furthermore, substitution of different cations into the perovskite lattice and/or the addition of precious metals were found to increase the sulfur tolerance [21, 26, 28-30]. Recently, Wang et al. [31] investigated $\mathrm{SO}_{2}$ tolerance and regeneration of $\mathrm{LaCo}_{1-x} \mathrm{Pt}_{x} \mathrm{O}_{3}$ in $\mathrm{NO}_{x}$ storage and reduction processes. They compared their perovskite catalyst with a conventional $\mathrm{Pt} / \mathrm{Ba} / \mathrm{Al}_{2} \mathrm{O}_{3} \mathrm{NSR}$ catalyst and reported that the perovskite had superior sulfur tolerance, regeneration capability and structural stability than the conventional NSR catalyst.

Recently, we have thoroughly investigated the synthesis, structural properties, $\mathrm{NO}_{x}$ oxidation/uptake and $\mathrm{NO}_{x}$ reduction behavior of $\mathrm{LaMnO}_{3}, \mathrm{Pd} / \mathrm{LaMnO}_{3}, \mathrm{LaCoO}_{3}$ and $\mathrm{Pd} / \mathrm{LaCoO}_{3}$ systems via transmission electron microscopy (TEM), X-ray diffraction (XRD), X-ray photoelectron spectroscopy (XPS), Raman spectroscopy, BET surface area analysis, in situ FTIR and TPD [32, 33]. In the current contribution, we focus on the molecular level investigation of the fundamental interactions that take place between $\mathrm{SO}_{x}$ species and $\mathrm{LaMnO}_{3}, \mathrm{Pd} / \mathrm{LaMnO}_{3}, \mathrm{LaCoO}_{3}$ and $\mathrm{Pd} /$ $\mathrm{LaCoO}_{3}$ catalyst surfaces. Generation, thermal evolution, reduction and release of S-related surface and bulk-like functional groups as a function of temperature in vacuum as well as in the presence of an external reducing agent were systematically monitored by means of in situ FTIR and TPD. Along these lines, the nature of the sulfur adsorption sites on these perovskite systems and the effect of sulfur poisoning on $\mathrm{NO}_{x}$ adsorption as well as catalytic regeneration behavior are discussed.

\section{Experimental}

\subsection{Catalyst Preparation}

$\mathrm{LaMnO}_{3}$ and $\mathrm{LaCoO}_{3}$ were prepared by using the citrate route [32]. For further details regarding the synthesis and structural characterization, the reader is referred to the discussion provided elsewhere [33]. Palladium supported perovskite materials was synthesized via conventional wetness impregnation method utilizing palladium nitrate along with $\mathrm{LaCoO}_{3}$ or $\mathrm{LaMnO}_{3}$, where the perovskite materials were originally calcined at $973 \mathrm{~K}$ for $5 \mathrm{~h}$ in air. The nominal Pd loading was $1.5 \mathrm{wt} \% \mathrm{Pd}$ in all of the synthesized catalysts. After the Pd loading, catalysts were further calcined at $773 \mathrm{~K}$ for $5 \mathrm{~h}$ in air.

\subsection{Instrumentation}

FTIR spectroscopic measurements were carried out in transmission mode in a batch-type catalytic reactor [9] coupled to an FTIR spectrometer (Bruker Tensor 27) and a quadruple mass spectrometer (QMS, Stanford Research Systems, RGA 200). All FTIR spectra were acquired at $323 \mathrm{~K}$. Prior to each experiment, materials were activated/cleaned using 2.0 Torr $\mathrm{NO}_{2}$ gas at room temperature followed by heating at $973 \mathrm{~K}$ for $5 \mathrm{~min}$ under vacuum. $\mathrm{NO}_{2}$ was prepared by the reaction of $\mathrm{NO}(99.9 \%$ purity, Air Products) with $\mathrm{O}_{2}(99.999 \%$ purity, Linde AG) and further purified by subsequent freeze-pump-thaw cycles.

Poisoning experiments were carried out by exposing the sample surfaces to 2.0 Torr $\mathrm{SO}_{2}+\mathrm{O}_{2}$ gas mixture $\left(\mathrm{SO}_{2}: \mathrm{O}_{2}=1: 10\right)$ at $300 \mathrm{~K}\left(\mathrm{SO}_{2}\right.$ purity $>99 \%$, Air Products). Then, samples were annealed to $323,373,473,573$, or $673 \mathrm{~K}$ and kept at these given temperatures for $15 \mathrm{~min}$ in the presence of the gas mixture. Thermal regeneration of the sulfur-poisoned perovskite catalysts was performed via annealing (heating rate $=12 \mathrm{~K} \mathrm{~min}^{-1}$ ) at temperatures within 473-1073 K, where the samples were kept at chosen temperatures for $10 \mathrm{~min}$ in vacuum. Desulfation/reduction experiments with $\mathrm{H}_{2}$ (99.995\% purity, Linde AG) were carried out by exposing the pre-sulfated samples (using the sulfation protocol given above) to 2.0 Torr of $\mathrm{H}_{2}$ at $300 \mathrm{~K}$ followed by heating at various temperatures (i.e. 673-873 $\mathrm{K}$ for $\mathrm{LaMnO}_{3}$, and 673-973 $\mathrm{K}$ for $\mathrm{LaCoO}_{3}$ ) in the presence of $\mathrm{H}_{2}$ for $15 \mathrm{~min}$. For the sequential $\mathrm{SO}_{x}$ and $\mathrm{CO}$ adsorption experiments, material surfaces were initially saturated with 50.0 Torr of CO $(\mathrm{g})(99.995 \%$ purity, Air Products) for $1 \mathrm{~h}$ at $323 \mathrm{~K}$ followed by evacuation at 
$\sim 10^{-3}$ Torr. Next, these CO pre-adsorbed surfaces were exposed to 2.0 Torr $\mathrm{SO}_{x}$ mixture $\left(\mathrm{SO}_{2}: \mathrm{O}_{2}=1: 10\right)$ at $323 \mathrm{~K}$.

$\mathrm{SO}_{x}$ TPD experiments were performed by initially exposing the materials with 2 Torr $\mathrm{SO}_{x}$ mixture $\left(\mathrm{SO}_{2}: \mathrm{O}_{2}=1: 10\right)$ at $673 \mathrm{~K}$ for $30 \mathrm{~min}$ followed by evacuating the reactor until the pressure reached $10^{-3}$ Torr. Then, materials were heated to $1173 \mathrm{~K}$ with a linear heating rate of $12 \mathrm{~K} \mathrm{~min}^{-1}$ in vacuum. $\mathrm{m} / \mathrm{z}=32$ [corresponding to $\mathrm{O}_{2}$ and $\mathrm{S}$ desorption where the latter is due to the impact ionization-induced fragmentation of desorbed $\mathrm{SO}_{2}$ (g) in QMS], $m / z=64$ [corresponding to $\mathrm{SO}_{2}$ (g) desorption] and $\mathrm{m} / \mathrm{z}=34$ [corresponding to $\mathrm{H}_{2} \mathrm{~S}$ (g) desorption] channels were monitored by QMS.

Ex-situ XPS analysis was performed using a SPECS photoelectron spectrometer equipped with a monochromatic Al Ka X-ray source (1486.74 eV, $200 \mathrm{~W}$ ) and a PHOIBOS-100 hemispherical energy analyzer with a MCD5 detector. Prior to the XPS analysis of the sulfur poisoned catalysts, catalyst surfaces were exposed to 10.0 Torr of $\mathrm{SO}_{2}+\mathrm{O}_{2}$ gas mixture $\left(\mathrm{SO}_{2}: \mathrm{O}_{2}=1: 10\right)$ and annealed at $673 \mathrm{~K}$ for $30 \mathrm{~min}$ in the presence of the gas mixture.

\section{Results and Discussion}

\subsection{Material Characterization}

The detailed characterization of perovskite materials via XRD, TEM, BET, XPS, and Raman Spectroscopy was previously reported in one of our former publications [33]. XRD patterns of these materials revealed only perovskite phases with a major diffraction signal at $32.56^{\circ}$ for $\mathrm{LaMnO}_{3}$ and $32.84^{\circ}, 33.21^{\circ}$ for $\mathrm{LaCoO}_{3}$. Pd or $\mathrm{PdO}_{x}$ were not detected in the XRD measurements, however, TEM and XPS investigation clearly verified the presence of $\mathrm{PdO} /$ $\mathrm{PdO}_{x}$ particles with an average particle size of ca. $4 \mathrm{~nm}$. The relative surface atomic ratio of perovskite samples determined by XPS measurements showed that the surface of these materials were enriched with lanthanum; most probably due to the presence of $\mathrm{La}_{2}\left(\mathrm{CO}_{3}\right)_{3}, \mathrm{La}(\mathrm{OH})_{3}$ and/or amorphous $\mathrm{La}_{2} \mathrm{O}_{3}$ domains.

\subsection{FTIR Spectroscopic Analysis of $\mathrm{SO}_{x}$ Uptake/ Release}

$\mathrm{SO}_{x}$ uptake and release properties of $\mathrm{LaMnO}_{3}$ and $\mathrm{Pd} /$ $\mathrm{LaMnO}_{3}$ perovskite materials were investigated via in situ FTIR as shown in Fig. 1. Sulfation of $\mathrm{LaMnO}_{3}$ and $\mathrm{Pd} /$ $\mathrm{LaMnO}_{3}$ reveals FTIR spectra with similar line shapes (bottom set of spectra in Fig. 1). Four main vibrational features at ca. 1240, 1140, 1058, and $987 \mathrm{~cm}^{-1}$ are observed. While two of the former features are assigned to bulk-like sulfates, the latter two are attributed to bidentate surface sulfate species $[13,15]$. The minor feature at $912 \mathrm{~cm}^{-1}$, which is observed at the initial stages of sulfation is assigned to sulfite-like species [29]. Thermal annealing of pre-sulfated surfaces to $1073 \mathrm{~K}$ revealed sharper features at $1179,1106,1064$, and $990 \mathrm{~cm}^{-1}$. The second quadruplet was previously associated with bulk or subsurface sulfates as these species showed higher resistance towards reduction by $\mathrm{NH}_{3}$ [34].

Considering the difference in scale bars of Fig. $1 \mathrm{a}, \mathrm{b}$ (i.e. 0.2 and 0.6; respectively), one can readily realize that sulfation of $\mathrm{Pd} / \mathrm{LaMnO}_{3}$ (Fig. 1b) leads to almost three times higher $\mathrm{SO}_{x}$-related IR absorption intensities as compared to that of Pd-free counterpart (Fig. 1a). Although it is not that feasible to make an accurate quantitative comparison of adsorbed $\mathrm{SO}_{x}$ species solely based on integrated FTIR spectra (due to differences in IR absorption cross sections of dissimilar oscillators and vibrational intensity transfer processes between oscillators [35]), it can be qualitatively argued that the presence of $\mathrm{Pd}$ leads to an increase in the $\mathrm{SO}_{x}$ uptake. This argument is also strongly supported by the XPS data that is presented in the forthcoming sections. It is most likely that exposed $\mathrm{Pd}$ sites catalyze the $\mathrm{SO}_{2}$ oxidation and facilitate the sulfate accumulation on the catalyst surface. This increase in sulfur adsorption can be also tentatively attributed to the modification in the oxygen mobility of the perovskite surface due to the partial substitution of Pd into the B-sites of the perovskite on the surface [26]. Thermal regeneration of sulfur species in vacuum (middle sets of spectra in Fig. 1) at 373-673 $\mathrm{K}$ does not reveal any significant changes in IR spectra of $\mathrm{LaMnO}_{3}$ and $\mathrm{Pd} / \mathrm{LaMnO}_{3}$. However, after annealing at $873 \mathrm{~K}$, the IR features associated with surface sulfates (i.e. $1058 / 1063$ and $987 / 993 \mathrm{~cm}^{-1}$ ) start to diminish. Most of the surface sulfur species are removed after annealing at $1073 \mathrm{~K}$ (Fig. 1a, b) while bulk-like sulfate related features at 1179, 1106, 1064, and $990 \mathrm{~cm}^{-1}$ still persist to exist even after high temperature thermal regeneration in vacuum [29, 36]. IR absorption intensities of the bulk sulfates are almost identical for both materials after the thermal treatment at $1073 \mathrm{~K}$ (note the difference in $y$-axis scale bars in Fig. 1a, b) in spite of the fact that $\mathrm{Pd} /$ $\mathrm{LaMnO}_{3}$ (Fig. 1b) initially adsorbs more $\mathrm{SO}_{x}$ than $\mathrm{LaMnO}_{3}$ (Fig. 1).

S-poisoned materials were also reduced under $\mathrm{H}_{2}$ atmosphere in the temperature range of $673-873 \mathrm{~K}$ as illustrated in the top most sets of spectra in Fig. 1. Sulfates formed on $\mathrm{LaMnO}_{3}$ are resilient to reduction up to $773 \mathrm{~K}$ (Fig. 1a), however, most of the bulk and surface sulfates are removed after reduction at $873 \mathrm{~K}$. On the other hand, the sulfates on $\mathrm{Pd} / \mathrm{LaMnO}_{3}$ are less stable under reducing conditions as shown in Fig. 1b. On the sulfated $\mathrm{Pd} /$ 
Fig. 1 FTIR spectra related to $\mathrm{SO}_{x}$ uptake and release properties of $\mathbf{a} \mathrm{LaMnO}_{3}$, and b $\mathrm{Pd} / \mathrm{LaMnO}_{3}$. Bottom set of spectra in each panel were acquired after $\mathrm{SO}_{x}$ exposure (2.0 Torr, $\mathrm{SO}_{2}: \mathrm{O}_{2}=1: 10$ ) at $323 \mathrm{~K}$, followed by annealing at $373,473,573$, and $673 \mathrm{~K}$ in the $\mathrm{SO}_{x}$ gas mixture for $15 \mathrm{~min}$. Middle set of spectra in each panel were acquired by heating at $473,573,673,873$, and $1073 \mathrm{~K}$ for 15 min under vacuum and after $\mathrm{SO}_{x}$ gas mixture was evacuated. Upper set of spectra were acquired by heating at 673,773 , and $873 \mathrm{~K}$ under 2.0 Torr of $\mathrm{H}_{2}(\mathrm{~g})$ for 15 min after $\mathrm{SO}_{x}$ gas mixture was evacuated. All spectra were acquired at $323 \mathrm{~K}$ in vacuum

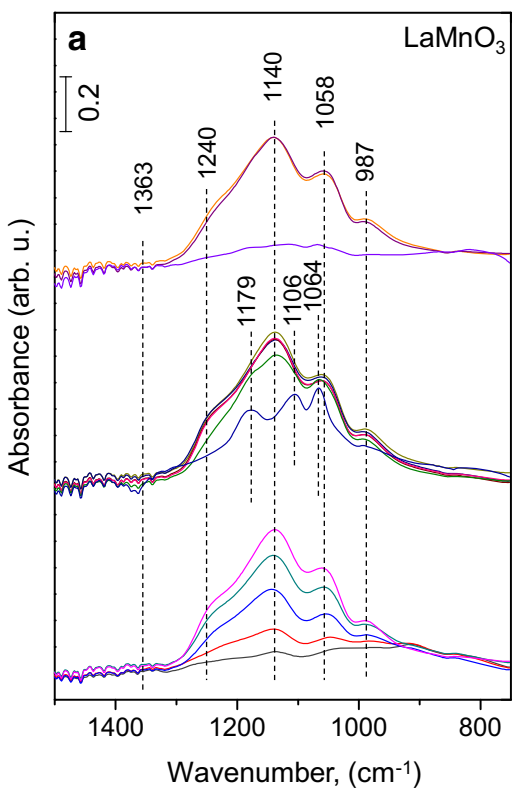

$\mathrm{LaMnO}_{3}$ catalyst (Fig. 1b), sulfate vibrational features significantly diminish even at $773 \mathrm{~K}$ and are completely removed at $873 \mathrm{~K}$ in the presence of hydrogen, while for $\mathrm{LaMnO}_{3}$ (Fig. 1a), a significant portion of sulfates continue to exist on the surface at $773 \mathrm{~K}$ in hydrogen. Enhancement of sulfate reduction via $\mathrm{H}_{2}$ in the presence of $\mathrm{Pd}$ can be explained by the dissociative chemisorption of $\mathrm{H}_{2}$ on $\mathrm{Pd}$ sites and $\mathrm{H}$-spill-over onto the perovskite surface [37]. A similar effect was also reported in the literature for an entirely different reaction where $\mathrm{Pd} / \mathrm{LaMnO}_{3}$ and $\mathrm{Pd} /$ $\mathrm{LaCoO}_{3}$ were found to exhibit higher methane conversion after sulfur regeneration via $\mathrm{H}_{2}$ [26].

Identical FTIR experiments were also performed for Cobased perovskite materials (Fig. 2). FTIR spectra acquired upon sulfation of $\mathrm{LaCoO}_{3}$ and $\mathrm{Pd} / \mathrm{LaCoO}_{3}$ at various temperatures (i.e. bottom set of spectra) are very similar to that of the Mn-based materials (Fig. 1). Thus, similar types of $\mathrm{SO}_{x}$ species seem to be forming on both $\mathrm{Mn}$ and $\mathrm{Co}-$

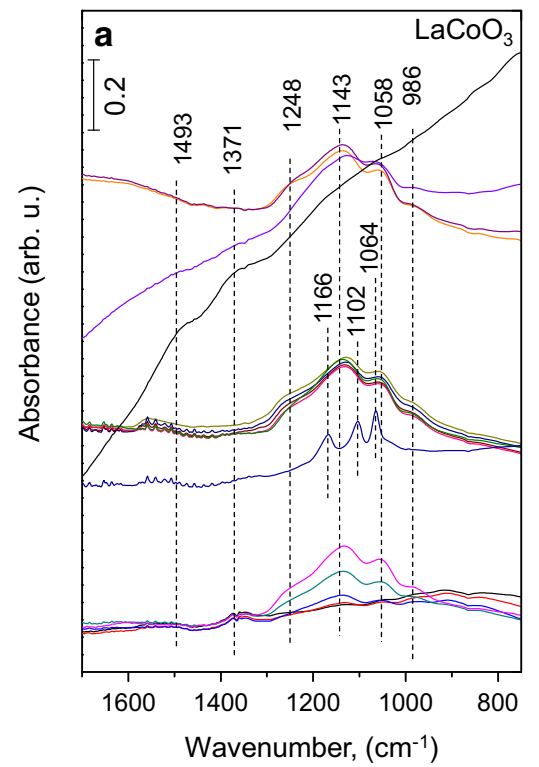

Fig. 2 FTIR spectra related to $\mathrm{SO}_{x}$ uptake and release properties of a $\mathrm{LaCoO}_{3}$, and $\mathbf{b} \mathrm{Pd} / \mathrm{LaCoO}_{3}$. Bottom set of spectra in each panel were acquired after $\mathrm{SO}_{x}$ exposure (2.0 Torr, $\mathrm{SO}_{2}: \mathrm{O}_{2}=1: 10$ ) at $323 \mathrm{~K}$, followed by annealing at $373,473,573$, and $673 \mathrm{~K}$ in the $\mathrm{SO}_{x}$ gas mixture for $15 \mathrm{~min}$. Middle set of spectra in each panel were

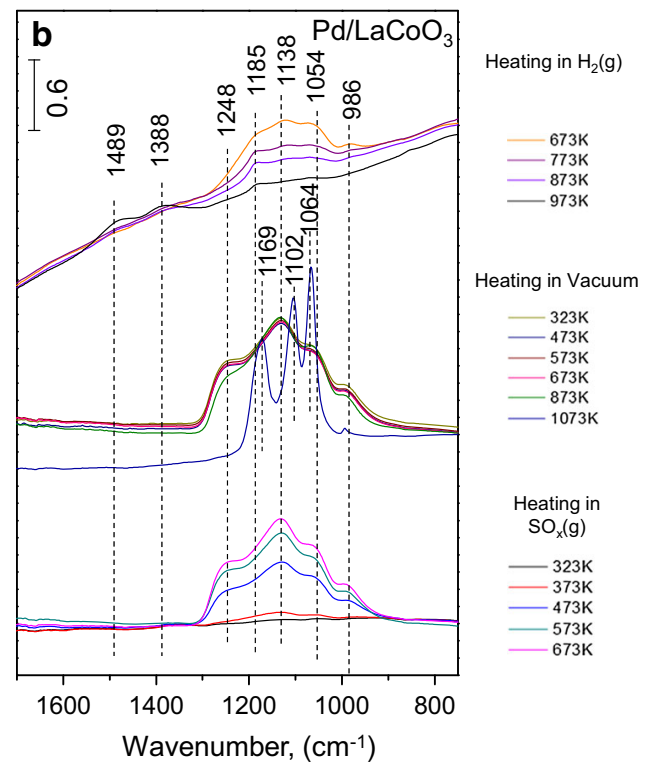

acquired by heating at $473,573,673,873$, and $1073 \mathrm{~K}$ for $15 \mathrm{~min}$ under vacuum and after $\mathrm{SO}_{x}$ gas mixture was evacuated. Upper set of spectra were acquired by heating at $673,773,873$, and $973 \mathrm{~K}$ under 2.0 Torr of $\mathrm{H}_{2}(\mathrm{~g})$ for 15 min after $\mathrm{SO}_{x}$ gas mixture was evacuated. All spectra were acquired at $323 \mathrm{~K}$ in vacuum 
based perovskites. Moreover, based on FTIR intensities (as well as the current XPS results that are discussed in the forthcoming sections) one can infer that $\mathrm{LaMnO}_{3}$ (Fig. 1a) reveals a higher sulfur accumulation as compared to $\mathrm{LaCoO}_{3}$ (Fig. 2a). It is likely that specific surface area (SSA) is one of the important factors that is responsible for the difference between the relative sulfur uptake of $\mathrm{Mn}$ and Co-based perovskites. As we have reported in a previous publication, SSA for $\mathrm{LaMnO}_{3}, \mathrm{Pd} / \mathrm{LaMnO}_{3}, \mathrm{LaCoO}_{3}$ and $\mathrm{Pd} / \mathrm{LaCoO}_{3}$ are 20.6, 21.9, 7.1, and $8.9 \mathrm{~m}^{2} \mathrm{~g}^{-1}$, respectively [33]. Thus, the higher SSA of Mn-based perovskites lead to a higher total $\mathrm{SO}_{x}$ uptake. As well as the surface area, relative surface basicity of perovskite materials also plays a significant role for $\mathrm{SO}_{2}$ adsorption capabilities. It was stated in the literature that $\mathrm{LaMnO}_{3}$ has a greater $\mathrm{CO}_{2}$ adsorption capacity than that of $\mathrm{LaCoO}_{3}$, indicating a greater surface basicity of the former perovskite [26].

Thermal stability of $\mathrm{SO}_{x}$ species on $\mathrm{LaCoO}_{3}$ and $\mathrm{Pd} /$ $\mathrm{LaCoO}_{3}$ in vacuum are presented in the middle sets of spectra given in Fig. 2. $\mathrm{SO}_{x}$ species on both surfaces are stable on the catalyst surfaces up to $873 \mathrm{~K}$. However, after annealing in vacuum at $1073 \mathrm{~K}$, the Co-based perovskite samples reveal stark changes corresponding to the formation of bulk sulfates evident by the vibrational features located at 1166, 1102, and $1064 \mathrm{~cm}^{-1}$ [34]. Furthermore, distinctly sharp vibrational features corresponding to these bulk sulfate species may be associated with the formation of well-defined/ordered metal-sulfate domains such as $\mathrm{La}_{2}\left(\mathrm{SO}_{4}\right)_{3}$ on the $\mathrm{LaCoO}_{3}$ and $\mathrm{Pd} / \mathrm{LaCoO}_{3}$ surfaces. This observation is consistent with a related work by Wang et al. who reported that on $\mathrm{La}_{0.9} \mathrm{Sr}_{0.1} \mathrm{CoO}_{3}, \mathrm{SO}_{2}$ led to the formation of $\mathrm{La}_{2}\left(\mathrm{SO}_{4}\right)_{3}$ on the surface and $\mathrm{La}_{2}\left(\mathrm{SO}_{4}\right)_{3}, \mathrm{La}_{2}$ $\left(\mathrm{SO}_{3}\right)_{3}, \mathrm{La}_{2} \mathrm{O}_{2} \mathrm{SO}_{4}$ and $\mathrm{CoO}, \mathrm{Co}_{3} \mathrm{O}_{4}$ in the bulk $[28,38]$.

Regeneration of the sulfated $\mathrm{LaCoO}_{3}$ and $\mathrm{Pd} / \mathrm{LaCoO}_{3}$ surfaces with $\mathrm{H}_{2}$ is shown in the topmost sets of spectra given Fig. 2. While $\mathrm{SO}_{x}$ species on $\mathrm{LaCoO}_{3}$ are mostly stable in $\mathrm{H}_{2}$ up to $773 \mathrm{~K}$, attenuation of $\mathrm{SO}_{x}$ vibrational features (located at 1248, 1185, 1138, 1054, and $986 \mathrm{~cm}^{-1}$ ) are observed in the case of $\mathrm{Pd} / \mathrm{LaCoO}_{3}$. Further reduction with $\mathrm{H}_{2}$ at higher temperatures within 773-973 K gradually diminishes the $\mathrm{SO}_{x}$ IR intensities for both $\mathrm{LaCoO}_{3}$ and $\mathrm{Pd} / \mathrm{LaCoO}_{3}$, where $\mathrm{SO}_{x}$ species seem to almost disappear after reduction at $973 \mathrm{~K}$. Unlike the Mn-based perovskites, where almost complete $\mathrm{SO}_{x}$ elimination was achieved at $873 \mathrm{~K}$ (upper sets of spectra in Fig. 1), $\mathrm{LaCoO}_{3}$ and $\mathrm{Pd} /$ $\mathrm{LaCoO}_{3}$ exhibit a relatively limited $\mathrm{SO}_{x}$ reduction capability in $\mathrm{H}_{2}$ (upper sets of spectra in Fig. 2). This can also be attributed to the formation of cobalt sulfates and partial destruction of the perovskite structure after the poisoning process [31, 39].

Reduction of the Co-based perovskites with $\mathrm{H}_{2}$ also reveals a very striking spectral alteration at elevated temperatures where the baselines of the IR spectra undergo a significant modification and become oblique. Considering the fact that optical conditions in the spectroscopic setup as well as the positioning of the catalysts in the spectroscopic cell were invariant, this baseline deviation might be associated with electronic and structural aberrations in the $\mathrm{LaCoO}_{3}$ and $\mathrm{Pd} / \mathrm{LaCoO}_{3}$ catalysts. It is likely that under these reducing conditions, the structural integrity of the Cobased perovskites was compromised, which may be associated with the reduction of the $\mathrm{Co}^{3+}$ (B-site) cations, partial destruction and phase segregation of the perovskite structure and formation of $\mathrm{Co} / \mathrm{CoO} / \mathrm{La}_{2} \mathrm{O}_{3}$ domains [25, 40-43]. This phenomenon has also been reported in one of our previous studies [33] where it was observed that interaction of Co-based perovskites with $\mathrm{H}_{2}$ in the absence of $\mathrm{SO}_{x}$ species also led to the partial destruction of the perovskite structure and the reduction of $\mathrm{Co}^{3+}$ sites. This particularly mild reduction phenomenon is rather reversible, where exposing the partially reduced Co-based perovskites to air under ambient conditions allows the recovery of the perovskite structure as verified by XPS, XRD and Raman spectroscopic analysis (data not shown). Thus, it is likely that the mild and reversible reduction process taking place during the current experiments on the Co-based perovskites predominantly affects the surface/ near-surface region of the catalysts without inflicting an irreversible bulk/deep reduction [41]. Furthermore, comparison of the extent of the baseline tilt upon reduction reveals a less prominent effect for $\mathrm{Pd} / \mathrm{LaCoO}_{3}$ compared to $\mathrm{LaCoO}_{3}$. This behavior has also been discussed in our former report [33], where we have demonstrated that Pdsupported perovskites has a favorable influence on the preservation of the structural stability of Co-based perovskites under reducing conditions. It should be noted that although $\mathrm{Pd} / \mathrm{LaCoO}_{3}$ was found to have the highest $\mathrm{NO}_{x}$ storage capacity among all other investigated perovskites [33], it has also a higher tendency for sulfur uptake.

\subsection{Quantitative Surface Analysis via XPS}

XPS analyses were performed in order to provide a semiquantitative basis for the relative sulfur uptake of the investigated catalytic architectures. Figure 3 presents Mn/ $\mathrm{La}$ and $\mathrm{S} / \mathrm{La}$ relative surface atomic ratios that were evaluated from the integrated intensities of the $\mathrm{Mn} 2 p, \mathrm{La} 3 d_{5 / 2}$ and $\mathrm{S} 2 p$ core level photoelectron spectra of the $\mathrm{LaMnO}_{3}$ and $\mathrm{Pd} / \mathrm{LaMnO}_{3}$ samples after sulfation or after reduction of sulfates in $\mathrm{H}_{2}(\mathrm{~g})$. Note that prior to the XPS measurements, samples were treated with significantly higher (i.e. fivefold greater) $\mathrm{SO}_{x}$ exposures as compared to that of the in situ FTIR experiments given in Figs. 1 and 2 in order to improve the signal to noise ratio $(\mathrm{S} / \mathrm{N})$ of the $\mathrm{S} 2 p$ XP spectra. The insets in Fig. 3 present FTIR spectra of the same samples investigated in the XPS experiments which 

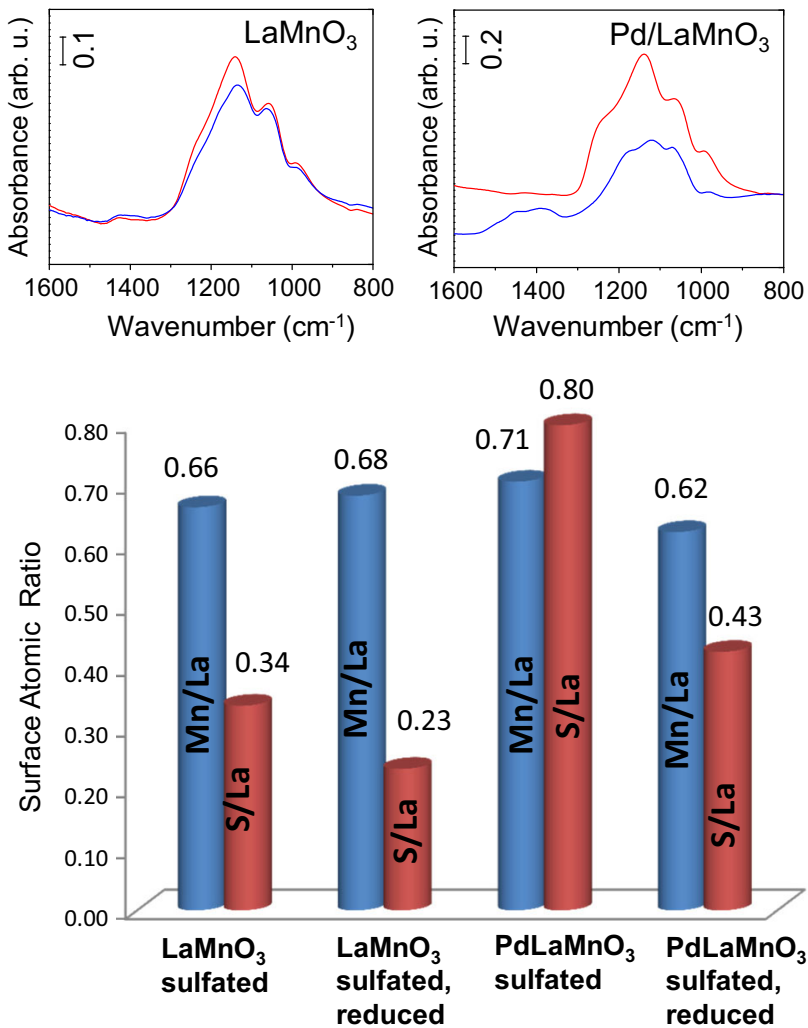

Fig. 3 Surface atomic ratios of sulfated (2.0 Torr, $\mathrm{SO}_{2}: \mathrm{O}_{2}=1: 10$ at $673 \mathrm{~K}$ ) and sulfated + reduced (under 2.0 Torr of $\mathrm{H}_{2}$ for $15 \mathrm{~min}$ at $773 \mathrm{~K}$ ) $\mathrm{LaMnO}_{3}$ and $\mathrm{Pd} / \mathrm{LaMnO}_{3}$ samples via XPS (see text for details). Insets present the FTIR spectra of the same samples investigated in the XPS experiments, where red and blue spectra correspond to sulfated and sulfated + reduced samples; respectively

were exposed to high levels of $\mathrm{SO}_{x}$. It should be noted that in all samples except $\mathrm{Pd} / \mathrm{LaMnO}_{3}$, which was sulfated and subsequently reduced, sulfur was found only in the form of $\mathrm{SO}_{4}{ }^{2-}$ (i.e. $\mathrm{S}^{6+}$ ). On the surface of the reduced $\mathrm{Pd} / \mathrm{LaMnO}{ }_{3}$ sample, along with sulfates, some sulfites and sulfides were also detected with a relative abundance of 100:10:15, respectively. The reduction of the sulfated $\mathrm{LaMnO}_{3}$ sample leads to a significant decrease in the $\mathrm{S} / \mathrm{La}$ ratio (i.e. by $\sim 30 \%$ ). Based on the XPS data, $\mathrm{Pd} / \mathrm{LaMnO}_{3}$ seems to accumulate twice the amount of $\mathrm{SO}_{x}$ with respect to $\mathrm{LaMnO}_{3}$. However, $\mathrm{Pd} / \mathrm{LaMnO}_{3}$ catalyst also seems to eliminate a greater fraction (ca. $45 \%$ ) of the adsorbed $\mathrm{SO}_{x}$ species upon reduction. These results are in good agreement with the corresponding FTIR spectra presented in the insets. The perovskite surfaces are enriched with lanthanum as was discussed in detail in one of former reports [33]. It is also worth mentioning that no appreciable changes in the surface $\mathrm{Mn} / \mathrm{La}$ ratios were detected after sulfation and reduction of both $\mathrm{LaMnO}_{3}$ and $\mathrm{Pd} / \mathrm{LaMnO}$ catalysts, reflecting the structural stability of these systems against sulfation and reduction with $\mathrm{H}_{2}$.
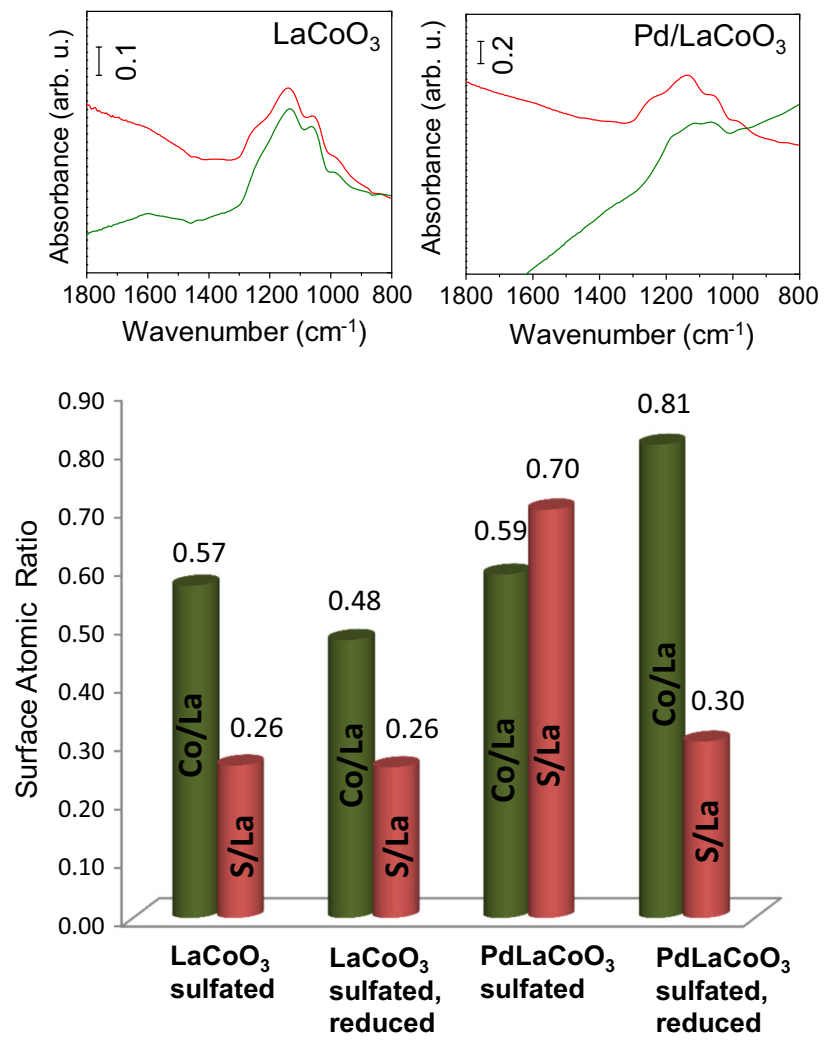

Fig. 4 Surface atomic ratios of sulfated (2.0 Torr, $\mathrm{SO}_{2}: \mathrm{O}_{2}=1: 10$ at $673 \mathrm{~K}$ ) and sulfated + reduced (under 2.0 Torr of $\mathrm{H}_{2}$ for $15 \mathrm{~min}$ at $773 \mathrm{~K}$ ) $\mathrm{LaCoO}_{3}$ and $\mathrm{Pd} / \mathrm{LaCoO}_{3}$ samples via XPS (see text for details). Insets present the FTIR spectra of the same samples investigated in the XPS experiments, where red and green spectra correspond to sulfated and sulfated + reduced samples; respectively

Similar XPS analysis measurements were also carried out for Co-based perovskite catalysts (Fig. 4). For the sulfated $\mathrm{LaCoO}_{3}$ and $\mathrm{Pd} / \mathrm{LaCoO}_{3}$ samples, sulfur was only found in the $\mathrm{S}^{6+}$ state (i.e. in the form of sulfates). On the other hand, for the sulfated and reduced $\mathrm{Pd} / \mathrm{LaCoO}_{3}$ sample, sulfite and sulfide species were also detected with relative $\mathrm{SO}_{4}{ }^{2-}$ :$\mathrm{SO}_{3}{ }^{2-}: \mathrm{S}^{2-}$ abundances of 100:11:35, respectively. The sulfur content does not decrease significantly upon reduction of the sulfated $\mathrm{LaCoO}_{3}$ sample. As in the case of Mn-based perovskites, $\mathrm{Pd}$ addition into the $\mathrm{LaCoO}_{3}$ system favorably enhances the regeneration performance under hydrogen. This is evident by the strong decrease in the S/La ratio (ca. $55 \%)$ of $\mathrm{Pd} / \mathrm{LaCoO}_{3}$ after reduction, in spite of the decrease in the relative abundance of $\mathrm{La}$ on the surface (i.e. attenuation of the $\mathrm{Co} / \mathrm{La}$ ratio after reduction of the poisoned surface). Relatively strong alterations in the $\mathrm{Co} / \mathrm{La}$ ratios of $\mathrm{LaCoO}_{3}$ and $\mathrm{Pd} / \mathrm{LaCoO}_{3}$ surfaces upon reduction reflects the relative instability of these perovskites under reducing conditions which is in agreement with the baseline tilt observed in the corresponding FTIR spectra given in the insets of Fig. 4 [25, 40-43]. 


\subsection{Preferential Adsorption Sites for $\mathrm{SO}_{x}(\mathrm{~g})$}

An important aspect that is worth investigating is to determine whether $\mathrm{SO}_{x}$ species has any preference for particular adsorption sites on the $\mathrm{Pd} / \mathrm{LaMnO}_{3}$ and $\mathrm{Pd} /$ $\mathrm{LaCoO}_{3}$ catalyst surfaces. In order to investigate this issue, $\mathrm{CO}$ was used as a probe molecule in the competitive sequential adsorption of $\mathrm{SO}_{x}$ and $\mathrm{CO}$. Since $\mathrm{CO}$ can potentially adsorb on both $\mathrm{Pd}$ and perovskite sites, its coadsorption/substitution with/by $\mathrm{SO}_{x}$ may yield some insight regarding poisoning of different adsorption sites on the catalyst surface. FTIR spectra recorded after $\mathrm{CO}$ saturation of the fresh and pre-sulfated (i.e. poisoned) $\mathrm{Pd} / \mathrm{LaMnO}_{3}$ surfaces are presented in Fig. 5. Adsorption of CO (50 Torr for $1 \mathrm{~h}$ at $323 \mathrm{~K}$ ) on fresh surface (top spectrum) reveals a set of vibrational features at 2070, 1980, 1931, 1504, 1463 , and $1346 \mathrm{~cm}^{-1}$. While the first feature in spectrum (a) of Fig. 5 (i.e. $2070 \mathrm{~cm}^{-1}$ ) corresponds to a-top coordination, the latter two features at 1980 and $1931 \mathrm{~cm}^{-1}$ correspond to $\mathrm{CO}$ adsorbed on two and threefold coordination sites on metallic Pd, respectively [44-48]. It is important to mention that XPS analysis of the $\mathrm{Pd} / \mathrm{LaMnO}_{3}$ and $\mathrm{Pd} / \mathrm{LaCoO}_{3}$ samples reported in our former studies [33] indicates the presence of exclusively oxidized Pd states (i.e. $\mathrm{Pd}^{2+}$ ) after the catalyst synthesis, without any indication of metallic Pd surface sites. Thus, it is apparent that in the presence of excess $\mathrm{CO}$ (i.e. 50 Torr), $\mathrm{PdO} / \mathrm{PdO}_{x}$ surface species are

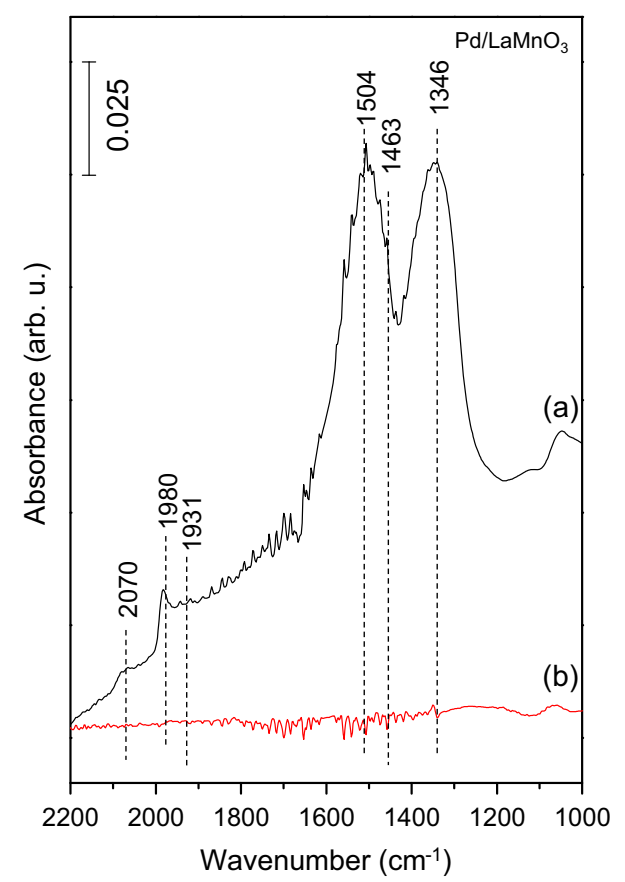

Fig. 5 FTIR spectra acquired after CO (g) adsorption [50.0 Torr of $\mathrm{CO}(\mathrm{g})$ for $1 \mathrm{~h}$ at $323 \mathrm{~K}$ ] on $a$ fresh $\mathrm{Pd} / \mathrm{LaMnO}_{3}$ and $b$ pre-sulfated (2.0 Torr, $\mathrm{SO}_{2}: \mathrm{O}_{2}=1: 10$, at $673 \mathrm{~K}$ ) $\mathrm{Pd} / \mathrm{LaMnO}_{3}$. All spectra were acquired at $323 \mathrm{~K}$ in vacuum reduced to metallic $\mathrm{Pd}^{0}$ species (Fig. 5). This argument is in very good agreement with previous observations reported in the literature, where Tessier et al. showed that surface $\mathrm{PdO}$ species can be readily reduced to metallic $\mathrm{Pd}$ in the presence of $\mathrm{CO}(\mathrm{g})$ at room temperature [49]. The lack of CO vibrational features within 2120-2110 and $2180-2160 \mathrm{~cm}^{-1}$ in Fig. 5, which are associated with CO adsorbed on $\mathrm{Pd}^{+}$and $\mathrm{Pd}^{2+}$ species [49], respectively; also indicates the absence of oxidized Pd surface sites on COsaturated $\mathrm{Pd} / \mathrm{LaMnO}_{3}$ surface.

On the other hand, vibrational features in Fig. 5 at 1504, 1463 , and $1346 \mathrm{~cm}^{-1}$ can be attributed to carbonate species on the perovskite sites of the $\mathrm{Pd} / \mathrm{LaMnO}_{3}$ surface due to the presence of Lewis-basic surface sites [50-52]. Lack of oxidized Pd adsorption sites due to the reducing effect of $\mathrm{CO}$ also enables us to rule out the presence of carbonates on the Pd-containing domains to a great extent, suggesting that carbonates are likely to be formed mostly on the perovskite sites. An identical $\mathrm{CO}$ exposure was also introduced over the pre-sulfated (2.0 Torr of $\mathrm{SO}_{2}+\mathrm{O}_{2}$ gas mixture, $\left.\mathrm{SO}_{2}: \mathrm{O}_{2}=1: 10,673 \mathrm{~K}, 30 \mathrm{~min}\right) \mathrm{Pd} / \mathrm{LaMnO}_{3}$ surface (bottom spectrum in Fig. 5) at $323 \mathrm{~K}$. Note that in this poisoning treatment, a high temperature of $673 \mathrm{~K}$ was employed, in order to ensure strong sulfation. No vibrational features related to $\mathrm{CO}$ adsorption was detected on the pre-sulfated $\mathrm{Pd} / \mathrm{LaMnO}_{3}$ surface indicating that both $\mathrm{Pd}$ and perovskite sites are poisoned simultaneously. FTIR

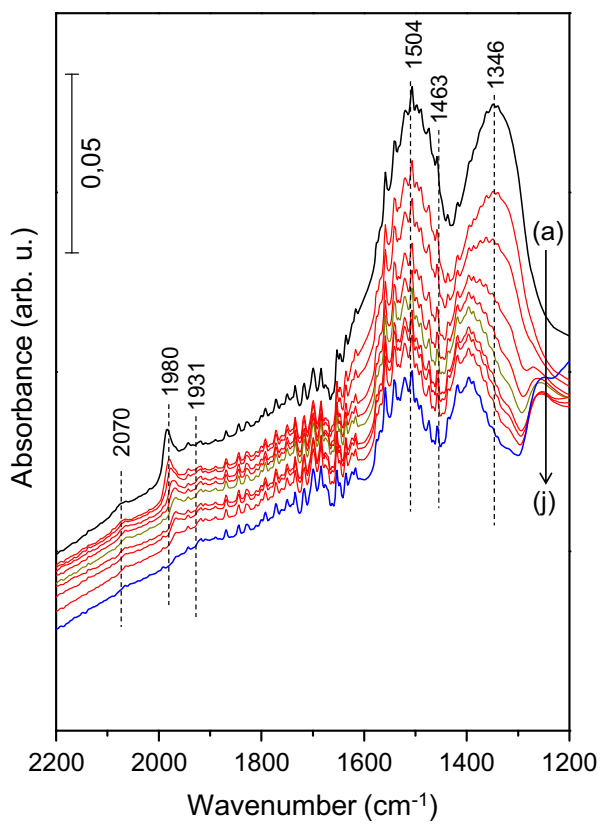

Fig. 6 FTIR spectra collected upon CO (g) adsorption [50.0 Torr of $\mathrm{CO}(\mathrm{g})$ for $1 \mathrm{~h}$ at $323 \mathrm{~K}$ ] on $a \mathrm{Pd} / \mathrm{LaMnO}_{3}$. Set of IR spectra from $b$ to $i$ were recorded by $\mathrm{SO}_{x}\left(\mathrm{SO}_{2}: \mathrm{O}_{2}=1: 10\right.$ at $323 \mathrm{~K}$ for $\left.1 \mathrm{~min}\right)$ exposure with incremental pressure in between 0.1 and 2.0 torr. Finally, $j$ corresponds to extreme $\mathrm{SO}_{x}\left(2.0\right.$ Torr, $\mathrm{SO}_{2}: \mathrm{O}_{2}=1: 10$ at $323 \mathrm{~K}$ for $5 \mathrm{~min}$ ) exposure. All spectra were acquired at $323 \mathrm{~K}$ in vacuum 
data presented in Fig. 5 clearly demonstrate that under extreme poisoning conditions, adsorption sites on the $\mathrm{Pd} /$ $\mathrm{LaMnO}_{3}$ catalyst surface are poisoned in a rather nonpreferential manner.

Figure 6 illustrates the FTIR experiments where $\mathrm{SO}_{x}$ mixture (2.0 Torr of $\mathrm{SO}_{2}+\mathrm{O}_{2}$ gas mixture $\left(\mathrm{SO}_{2}: \mathrm{O}_{2}=1: 10\right.$ ) was gradually introduced over the $\mathrm{CO}$ pre-adsorbed (topmost black spectra) surface. In these set of experiments gradual displacement of the relatively weakly bound pre-adsorbed $\mathrm{CO}$ species with strongly bound $\mathrm{SO}_{x}$ species are apparent. Spectra in Fig. 6 suggest that $\mathrm{SO}_{x}$ species can readily substitute relatively weakly adsorbed carbonyl functionalities on the Pd sites [45, 53], while carbonate species formed on the perovskite sites reveal a stronger resistance against displacement due to their relatively higher adsorption energy [54]. In addition, these results also do not rule out the possibility that Pd sites can be relatively more prone to sulfur poisoning with respect to that of the perovskite adsorption sites during the initial stages of poisoning. Under regular operational regime of a $\mathrm{DeNO}_{x}$ catalyst, a significant amount of $\mathrm{CO}$ and $\mathrm{CO}_{2}$ exists in the gas stream together with $\mathrm{SO}_{x}$ species. Thus, it is likely that carbonate functionalities located on the perovskite domains may direct the $\mathrm{SO}_{x}$ species towards the available $\mathrm{Pd}$ sites during the initial stages of poisoning. In other words, it is plausible that Pd sites may function as sacrificial sites at least during the initial stages of sulfur poisoning. Considering the operation of an NSR catalyst where the catalyst undergoes frequent switches between lean (i.e. oxidizing atmosphere where competitive $\mathrm{NO}_{x} / \mathrm{CO}_{x} / \mathrm{SO}_{x}$ uptake occurs) and rich (i.e. reducing atmosphere where $\mathrm{NO}_{x} /$ $\mathrm{CO}_{x} / \mathrm{SO}_{x}$ reduction takes place) cycles; the catalyst is typically in a partially-poisoned state. Thus, the sulfur poisoning behavior of such catalytic systems may be predominantly governed by the initial stages of $\mathrm{SO}_{x}$ uptake as described above.

It is worth mentioning that similar competitive $\mathrm{CO} / \mathrm{SO}_{x}$ adsorption experiments were also carried out on the $\mathrm{Pd} /$ $\mathrm{LaCoO}_{3}$ catalyst. However since this surface is opaque to the transmission of IR radiation above $1700 \mathrm{~cm}^{-1}$, (i.e. the IR spectral region where the metal carbonyl features are located), no comparable data was obtained in these experiments. However, based on the similarities in the $\mathrm{NO}_{x}$ [33] and $\mathrm{SO}_{x}$ adsorption properties of $\mathrm{Pd} / \mathrm{LaMnO}_{3}$ and $\mathrm{Pd} / \mathrm{LaCoO}_{3}$ surfaces, we anticipate a similar interplay between $\mathrm{CO}$ and $\mathrm{SO}_{x}$ on $\mathrm{Pd} / \mathrm{LaCoO}_{3}$ as in the case of $\mathrm{Pd} /$ $\mathrm{LaMnO}_{3}$.

\subsection{Effect of S-poisoning on the $\mathrm{NO}_{x}$ Adsorption Capacity of Perovskites}

Figure 7 illustrates FTIR spectra taken after $\mathrm{NO}_{x}$ saturation of fresh and sulfated $\mathrm{LaMnO}_{3}$ and $\mathrm{Pd} / \mathrm{LaMnO}_{3}$ samples. The black spectra correspond to $\mathrm{NO}_{x}$ adsorption on fresh material and red spectra correspond to $\mathrm{NO}_{x}$ adsorption on pre-sulfated material surface. Assignment of the nitrate/ nitrite absorption features on fresh perovskite surfaces was discussed comprehensively in one of our former reports [33]. Briefly, IR features located at around 1649 and $1009 \mathrm{~cm}^{-1}$ can be assigned to asymmetric and symmetric stretching modes of bridging nitrate species on the perovskite surfaces, respectively [55]. Features located at 1530 and $1269 \mathrm{~cm}^{-1}$ can be attributed to stretching vibrations of monodentate nitrates. The IR features at 1568 and $1246 \mathrm{~cm}^{-1}$ correspond to bidentate nitrates [56, 57]. The set of characteristic features observed at 1487, 1430, 1321 , and $839 \mathrm{~cm}^{-1}$ can be ascribed to nitrito species on the perovskite surface [58-61]. It should be noted that $\mathrm{NO}_{x}$ species (i.e. nitrites and nitrates) residing on $\mathrm{Pd}$ sites are difficult to discern from the $\mathrm{NO}_{x}$ species adsorbed on the perovskite domains due to the relatively low loading of $\mathrm{Pd}$ present in the catalyst formulation as well as the overlapping vibrational frequencies. Thus, the competitive adsorption trends observed for the data presented in Figs. 6 is not trivially visible in the data presented in Figs. 7 and 8.

It is obvious that pre-sulfation leads to suppression of nitrate/nitrite related features of $\mathrm{NO}_{x}$ saturated $\mathrm{LaMnO}_{3}$ and $\mathrm{Pd} / \mathrm{LaMnO}_{3}$ samples demonstrating competition between $\mathrm{SO}_{x}$ and $\mathrm{NO}_{2}$ for the same adsorption sites (Fig. 7). Suppression of the nitrate/nitrite features upon $\mathrm{NO}_{2}$ adsorption after sulfur poisoning can be readily explained by the occupation of some of the $\mathrm{NO}_{x}$ adsorption sites by the thermodynamically more stable surface sulfate species and formation of species such as $\mathrm{La}_{2}\left(\mathrm{SO}_{4}\right)_{3}[28,38,62]$. In Fig. 7a, relative vibrational intensity of $1322 \mathrm{~cm}^{-1}$ (nitrite species) diminishes more visibly as compared to the feature at $1263 \mathrm{~cm}^{-1}$ (monodentate nitrates) after sulfur poisoning. Similarly, on $\mathrm{Pd} / \mathrm{LaMnO}_{3}$ (Fig. 7b), attenuation in the relative vibrational intensity of $1328 \mathrm{~cm}^{-1}$ (nitrite species) is more pronounced as compared to that of $1279 \mathrm{~cm}^{-1}$ (monodentate nitrates) upon sulfur poisoning. This behavior reveals that monodentate geometry of surface nitrates becomes more preferable after sulfation of the surfaces probably due to the limited number of available perovskite adsorption sites on the poisoned materials.

As already demonstrated in our previous report [33], the total $\mathrm{NO}_{2}$ adsorption capacity of fresh $\mathrm{LaMnO}_{3}$ and $\mathrm{Pd} /$ $\mathrm{LaMnO}_{3}$ are comparable to each other. However, after sulfur poisoning, $\mathrm{Pd} / \mathrm{LaMnO}_{3}$ accumulates less $\mathrm{NO}_{2}$. Figure 7a indicates that the IR bands associated with the $\mathrm{NO}_{x}$ species on the Pd-free $\mathrm{LaMnO}_{3}$ sample have a moderate attenuation upon S-poisoning. On the other hand, the $\mathrm{Pd} /$ $\mathrm{LaMnO}_{3}$ sample (Fig. 7b) reveals a stronger attenuation. This is in perfect agreement with the results presented in previous sections suggesting that Pd-supported perovskite materials leads to higher $\mathrm{SO}_{x}$ accumulation/adsorption on the surface. 


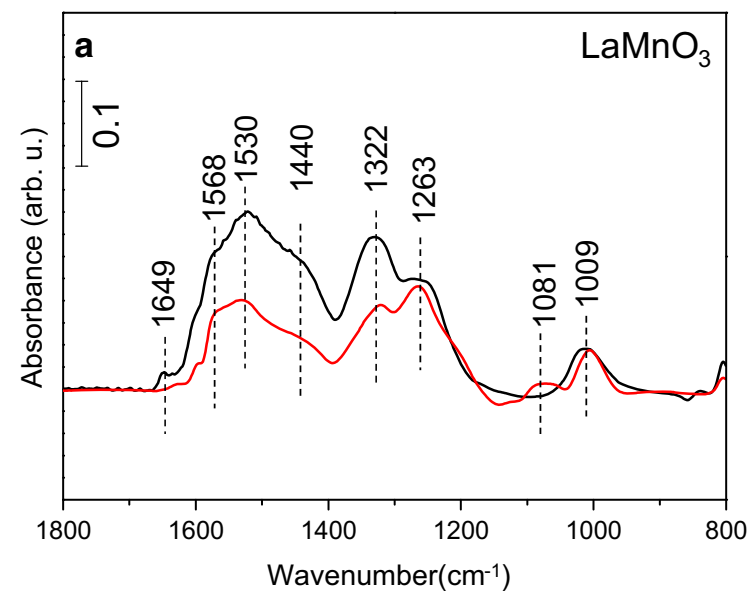

Fig. 7 FTIR spectra acquired after $\mathrm{NO}_{2}$ saturation [5.0 Torr $\mathrm{NO}_{2}(\mathrm{~g})$, $323 \mathrm{~K}, 10 \mathrm{~min}$ ] of fresh (black spectra) and S-poisoned surfaces (red spectra) via 2.0 Torr, $673 \mathrm{~K}, \mathrm{SO}_{2}: \mathrm{O}_{2}=1: 10$. a $\mathrm{LaMnO}_{3}$ and $\mathbf{b} \mathrm{Pd} /$

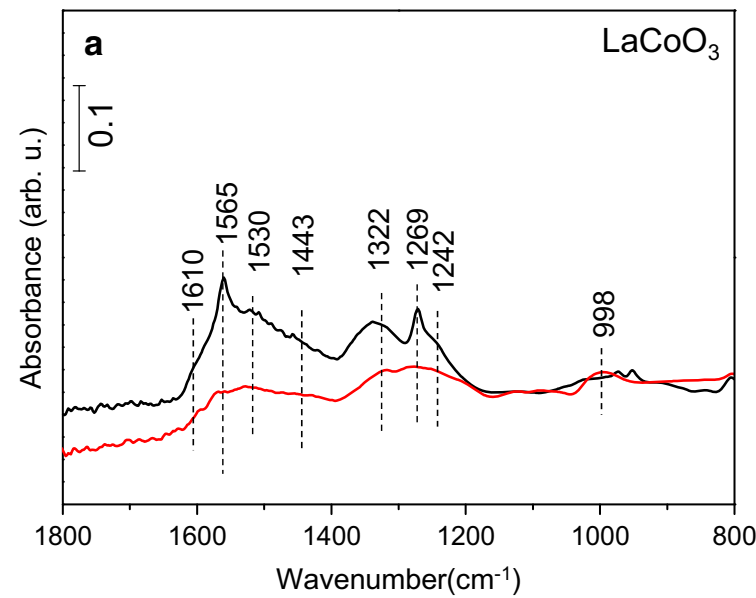

Fig. 8 FTIR spectra acquired after $\mathrm{NO}_{2}$ saturation [5.0 Torr $\mathrm{NO}_{2}(\mathrm{~g})$, $323 \mathrm{~K}, 10 \mathrm{~min}$ ] of fresh (black spectra) and S-poisoned surfaces (red spectra) via 2.0 Torr, $673 \mathrm{~K}, \mathrm{SO}_{2}: \mathrm{O}_{2}=1: 10$. a $\mathrm{LaCoO}_{3}$ and b $\mathrm{Pd} /$

An identical set of experiments was also performed for the $\mathrm{LaCoO}_{3}$ and $\mathrm{Pd} / \mathrm{LaCoO}_{3}$ materials (Fig. 8). After sulfation, the $1322 \mathrm{~cm}^{-1}$ (nitrito species) and $1242 \mathrm{~cm}^{-1}$ (bidentate nitrates) bands are suppressed while the band at $1293 \mathrm{~cm}^{-1}$ (monodentate nitrates) still persists. Thus, as in the case of Mn-based perovskite systems, Co-based perovskites also lose their $\mathrm{NO}_{x}$ storage capacity significantly upon $\mathrm{SO}_{x}$ poisoning with the formation of lanthanum and cobalt sulfate species [28, 31, 38, 39].

\subsection{Sulfur Regeneration Under Vacuum via TPD Analysis}

TPD experiments were carried out in order to examine the thermal regeneration characteristics as well as the relative adsorption strengths of adsorbed sulfur species on each synthesized perovskite material in the absence of an

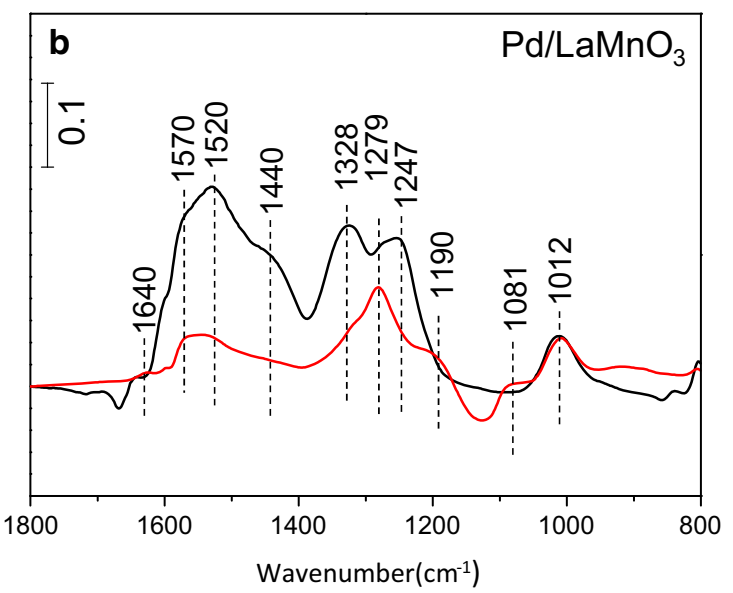

$\mathrm{LaMnO}_{3}$. All spectra were acquired at $323 \mathrm{~K}$ in vacuum. Note that the background FTIR spectra for the red curves were obtained after sulfur poisoning and before $\mathrm{NO}_{2}$ adsorption

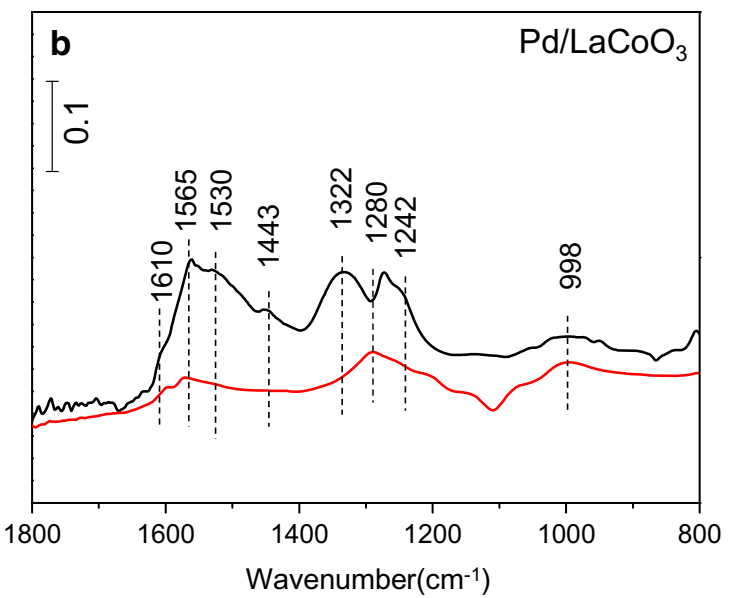

$\mathrm{LaCoO}_{3}$. All spectra were acquired at $323 \mathrm{~K}$ in vacuum. Note that the background FTIR spectra for the red curves were obtained after sulfur poisoning and before $\mathrm{NO}_{2}$ adsorption

external reducing agent. Only $\mathrm{O}_{2}, \mathrm{H}_{2} \mathrm{~S}$, and $\mathrm{SO}_{2}$ desorption channels (corresponding to mass to charge ratios of $m / z=32,34$, and 64; respectively) revealed significant QMS signals during the TPD experiments. Note that since the contribution of $\mathrm{SO}_{2}$ and $\mathrm{H}_{2} \mathrm{~S}$ to the $\mathrm{m} / z=32$ desorption signal is relatively minor. Thus, $\mathrm{m} / \mathrm{z}=32$ desorption channel can be predominantly attributed to $\mathrm{O}_{2}$ desorption. Figure 9 presents the TPD profiles for $m / z=32$ and 64 (i.e. $\mathrm{O}_{2}$ and $\mathrm{SO}_{2}$ desorption channels; respectively) regarding the thermal decomposition of pre-adsorbed sulfate and sulfite species on (a) $\mathrm{LaMnO}_{3}$, (b) $\mathrm{Pd} / \mathrm{LaMnO}_{3}$, (c) $\mathrm{LaCoO}_{3}$, and (d) $\mathrm{Pd} / \mathrm{LaCoO}_{3}$ surfaces; respectively. Sulfur-related species revealed high thermal stability for all of the synthesized materials which is evident by the lack of any desorption/decomposition signals at $\mathrm{T}<850 \mathrm{~K}$. Analysis of the similar line shapes for the $\mathrm{O}_{2}$ and $\mathrm{SO}_{2}$ traces revealing similar intensities and similar thermal 

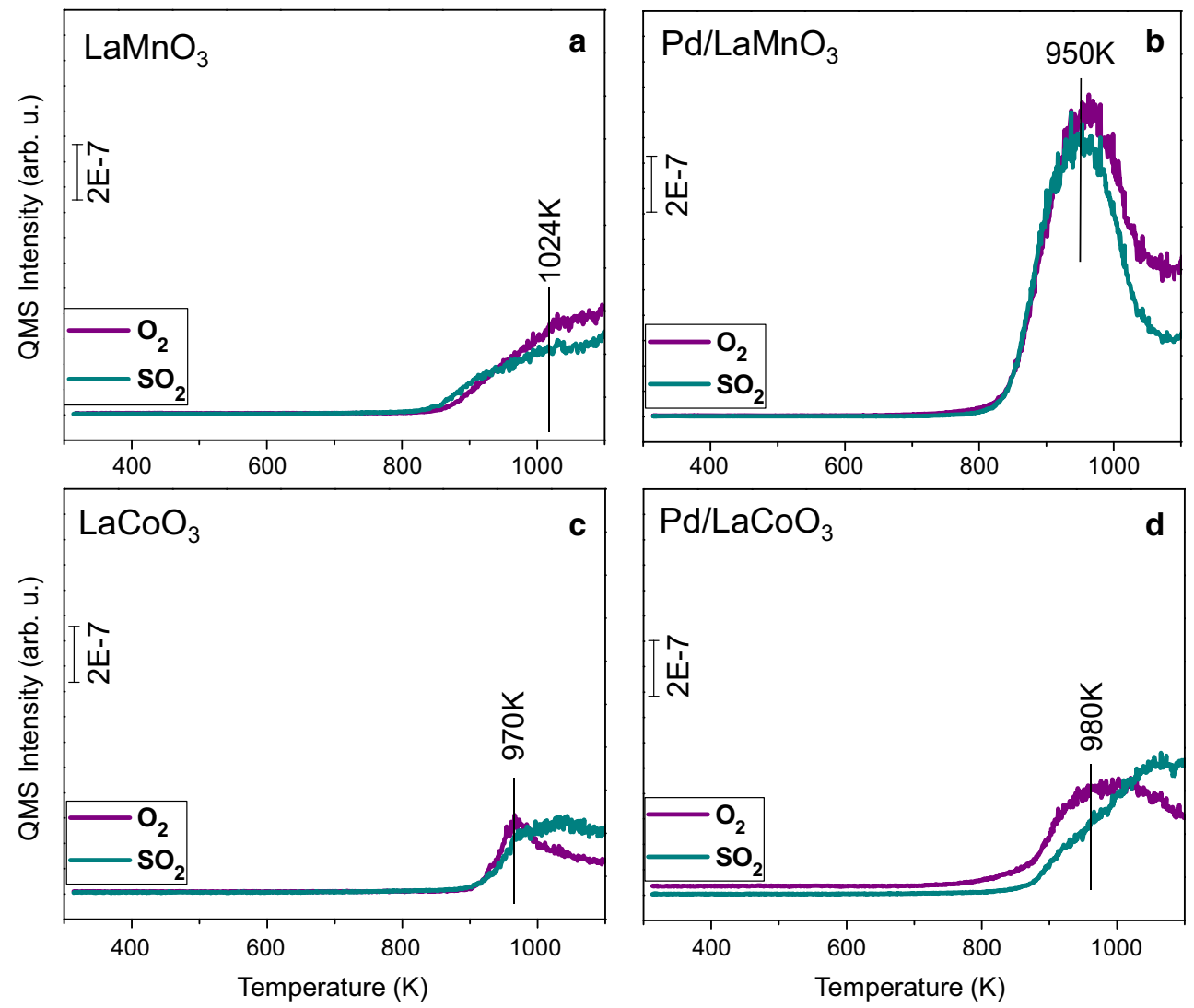

Fig. 9 TPD profiles for a $\mathrm{LaMnO}_{3}$, b Pd/LaMnO 3, c $\mathrm{LaCoO}_{3}$ and d Pd/LaCoO 3 after 2.0 Torr $\mathrm{SO}_{x}\left(2 \mathrm{Torr}^{\mathrm{SO}} \mathrm{S}_{2}+\mathrm{O}_{2}, \mathrm{SO}_{2}: \mathrm{O}_{2}=1: 10\right)$ adsorption at $673 \mathrm{~K}$ for $30 \mathrm{~min}$

dependences in Fig. 9a suggests that within the thermal window investigated in the TPD experiments (i.e. 323-1073 K), sulfates desorb in the form of $\mathrm{SO}_{2}(\mathrm{~g})+\mathrm{O}_{2}$ (g) from the $\mathrm{LaMnO}_{3}$ surface. It is also apparent in Fig. 9a that the maximum temperature that can be attained in the current TPD setup (i.e. $1073 \mathrm{~K}$ ) is not sufficient to remove most of the $\mathrm{SO}_{x}$ species from the $\mathrm{LaMnO}_{3}$ surface evident by the monotonically increasing desorption signals with increasing temperature without any desorption maxima. In other words, thermal $\mathrm{SO}_{x}$ desorption maximum of $\mathrm{LaMnO}_{3}$ is located at $\mathrm{T}>1073 \mathrm{~K}$. This is in perfect agreement with the in situ FTIR spectra presented in the middle section of Fig. 1a, corresponding to experiments reflecting similar conditions. On the other hand, $\mathrm{SO}_{x}$-TPD data for the $\mathrm{Pd} /$ $\mathrm{LaMnO}_{3}$ (Fig. 9b) indicates noticeable dissimilarities both in terms of relative desorption temperatures and desorption intensities as compared to that of Fig. 9a. For Pd/LaMnO $\mathrm{m} / \mathrm{z}=32$ and $\mathrm{m} / \mathrm{z}=64$ desorption channels reveal intense temperature maxima at ca. $950 \mathrm{~K}$. It is apparent that the presence of $\mathrm{Pd}$ sites noticeably facilitates the thermal decomposition of $\mathrm{SO}_{x}$ species in the form of $\mathrm{SO}_{2}(\mathrm{~g})+\mathrm{O}_{2}$ $(\mathrm{g})$. This observation is in very good agreement with the in situ FTIR data given in the middle section of Fig. $1 \mathrm{~b}$ at $1073 \mathrm{~K}$, representing conditions that are comparable to the ones corresponding to the completion of the TPD experiments.

Figure 9c, d show similar $\mathrm{SO}_{x}$-TPD experiments for $\mathrm{LaCoO}_{3}$ and $\mathrm{Pd} / \mathrm{LaCoO}_{3}$ catalysts; respectively. The most prominent feature of these TPD data are the relatively weak desorption maxima located at ca. 970-980 K suggesting the simultaneous evolution of $\mathrm{SO}_{2}(\mathrm{~g})+\mathrm{O}_{2}(\mathrm{~g})$. However, unlike the data in Fig. 9a, b, TPD data given in Fig. 9c, d also present a shoulder at $\mathrm{T}>1000 \mathrm{~K}$ where $\mathrm{O}_{2}(\mathrm{~g})$ desorption intensity exceeds that of the $\mathrm{SO}_{2}(\mathrm{~g})$ signal. This observation suggests that at elevated temperatures, it is likely that in addition to the thermal decomposition of sulfates $\left[\mathrm{SO}_{4}{ }^{2-}\right.$ (ads, bulk)], cobalt-based perovskites also undergo thermal reduction at elevated temperatures leading to the formation of oxygen vacancies, partial destruction of the perovskite lattice and the formation of thermallystable new species such as $\mathrm{La}_{2}\left(\mathrm{SO}_{4}\right)_{3}, \mathrm{La}_{2}\left(\mathrm{SO}_{3}\right)_{3}, \mathrm{CoSO}_{4}$, $\mathrm{CoSO}_{3}, \mathrm{Co}_{2}\left(\mathrm{SO}_{3}\right)_{3}$, and $\mathrm{Co}_{2}\left(\mathrm{SO}_{4}\right)_{3}$. This argument is in line with the formation of sharp and intense vibrational features for the $1073 \mathrm{~K}$ spectra in the middle section of the Fig. 2a, b.

Figure 10 shows the $m / z=34$ desorption channel corresponding to $\mathrm{H}_{2} \mathrm{~S}(\mathrm{~g})$ evolution which is acquired simultaneously with the set of TPD spectra given in Fig. 9. It is 


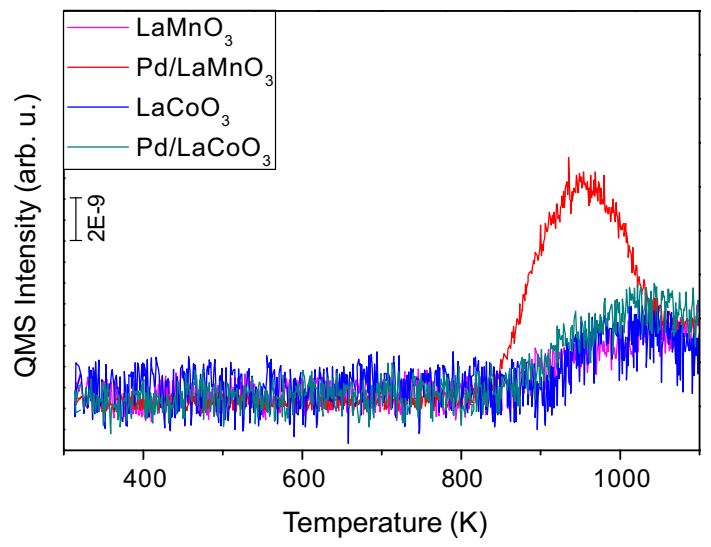

Fig. $10 \mathrm{H}_{2} \mathrm{~S}$ desorption profiles for $\mathrm{LaMnO}_{3}, \mathrm{Pd} / \mathrm{LaMnO}_{3}, \mathrm{LaCoO}_{3}$ and $\mathrm{Pd} / \mathrm{LaCoO}_{3}$ after 2.0 Torr $\mathrm{SO}_{x} \quad\left(2 \mathrm{Torr} \quad \mathrm{SO}_{2}+\mathrm{O}_{2}\right.$, $\mathrm{SO}_{2}: \mathrm{O}_{2}=1: 10$ ) adsorption at $673 \mathrm{~K}$ for $30 \mathrm{~min}$

apparent in Fig. 10 that within the investigated thermal window, $\mathrm{H}_{2} \mathrm{~S}$ evolution is relatively limited for all samples except for $\mathrm{Pd} / \mathrm{LaMnO}_{3}$. This can possibly be attributed to two factors. Firstly, the SSA of $\mathrm{Pd} / \mathrm{LaMnO}_{3}$ is almost three times greater than that of the $\mathrm{LaCoO}_{3}$ and $\mathrm{Pd} / \mathrm{LaCoO}_{3}$ catalysts. Thus, on the $\mathrm{Pd} / \mathrm{LaMnO}_{3}$ catalyst, the presence of -OH minority species might be more pronounced than the cobalt-based samples, allowing the observation of a more significant $\mathrm{H}_{2} \mathrm{~S}$ (g) desorption signal. Secondly, it is also probable that $\mathrm{H}_{2} \mathrm{~S}$ ( $\mathrm{g}$ ) desorption process is catalyzed by the surface Pd sites, as it is not observed on the $\mathrm{LaMnO}_{3}$ surface which lacks any Pd species.

\section{Conclusions}

In the current work, $\mathrm{LaMnO}_{3}, \mathrm{Pd} / \mathrm{LaMnO}_{3}, \mathrm{LaCoO}_{3}$ and $\mathrm{Pd} /$ $\mathrm{LaCoO}_{3}$ perovskite catalysts were synthesized and their structural as well as sulfur poisoning properties were thoroughly studied by means of in situ FTIR spectroscopy, XPS, and TPD. Our findings can be summarized as follows:

- $\mathrm{SO}_{x}$ adsorption capacity of $\mathrm{LaMnO}_{3}$ (per mass of catalyst) is greater than that of $\mathrm{LaCoO}_{3}$. This can tentatively be attributed to the significantly higher specific surface area.

- $\mathrm{SO}_{x}$ adsorption capacity significantly increases in the presence of Pd for both Mn- and Co-based perovskites.

- On Co-based perovskite systems, surface sulfates transform (at least partially) into stable bulk sulfate species at $\mathrm{T} \geq 1073 \mathrm{~K}$ in the absence of a reducing agent.

- Sulfates on $\mathrm{LaMnO}_{3}$ and $\mathrm{LaCoO}_{3}$ are resilient against reduction by $\mathrm{H}_{2}$ and can be eliminated only at elevated temperatures (i.e. $\mathrm{T}>873 \mathrm{~K}$ ) under reducing conditions. On the other hand, sulfates on Pd-containing perovskites can be reduced at lower temperatures such as $773 \mathrm{~K}$ in the presence of $\mathrm{H}_{2}$.

- Competitive $\mathrm{CO}$ and $\mathrm{SO}_{x}$ adsorption experiments suggest that Pd sites reveal a greater tendency towards $\mathrm{SO}_{x}$ species particularly in the early stages of sulfur poisoning as compared to the perovskite surface sites. Thus, $\mathrm{Pd}$ sites may function as sacrificial $\mathrm{SO}_{x}$ storage sites in the early stages of sulfur poisoning.

- $\mathrm{SO}_{x}$ species significantly attenuate the $\mathrm{NO}_{2}$ and $\mathrm{CO}$ adsorption capacities. However, even after severe $\mathrm{SO}_{x}$ poisoning, $\mathrm{NO}_{x}$ adsorption on perovskite systems can still continue to occur in the form of monodentate nitrates and nitrites.

- Even if Co-containing perovskites have higher $\mathrm{NO}_{x}$ storage capacity, Mn-based perovskites have higher stability against $\mathrm{H}_{2}$ and are more resilient against sulfur poisoning rendering the latter catalysts promising for NSR applications.

Acknowledgments The authors acknowledge the financial support from the Scientific and Technical Research Council of Turkey (TUBITAK) (Project Code: 213M585 and TUBITAK 2221 Fellowship Program). Authors also acknowledge the scientific collaboration with TARLA project founded by the Ministry of Development of Turkey under grant no DPT2006K-120470.

\section{References}

1. Epling WS, Campbell LE, Yezerets A, Currier NW, Parks JE (2004) Catal Rev 46:163-245

2. Matsumoto S (2000) Cattech 4:102-109

3. Roy S, Baiker A (2009) Chem Rev 109:4054-4091

4. Kato K, Nohira H, Nakanishi K, Iguchi S, Kihara T, Muraki H (1993) Euro Patent Application 0,573,672 A1

5. Myioshi N, Matsumoto S, Katoh K, Tanaka T, Harada K, Takahashi N, Yokota K, Sugiura M, Kasahara K (1995) SAE Technical Papers Series No. 950809

6. Takahashi N, Shinjoh H, Iijima T, Suzuki T, Yamazaki K, Yokota K, Suzuki H, Miyoshi N, Matsumoto S, Tanizawa T, Tanaka T, Tateishi S, Kasahara K (1996) Catal Today 27:63-69

7. Ozensoy E, Peden CHF, Szanyi J (2006) J Catal 243:149-157

8. Andonova SM, Senturk GS, Kayhan E, Ozensoy E (2009) J Phys Chem C 113:11014-11026

9. Kayhan E, Andonova SM, Senturk GS, Chusuei CC, Ozensoy E (2009) J Phys Chem C 114:357-369

10. Andonova SM, Senturk GS, Ozensoy E (2010) J Phys Chem C 114:17003-17016

11. Emmez E, Vovk EI, Bukhtiyarov VI, Ozensoy E (2011) J Phys Chem C 115:22438-22443

12. Vovk EI, Emmez E, Erbudak M, Bukhtiyarov VI, Ozensoy E (2011) J Phys Chem C 115:24256-24266

13. Senturk GS, Vovk EI, Zaikovskii VI, Say Z, Soylu AM, Bukhtiyarov VI, Ozensoy E (2012) Catal Today 184:54-71

14. Hummatov R, Gulseren O, Ozensoy E, Toffoli D, Ustunel H (2012) J Phys Chem C 116:6191-6199

15. Say Z, Vovk EI, Bukhtiyarov VI, Ozensoy E (2013) Top Catal 56:950-957 
16. Vovk EI, Turksoy A, Bukhtiyarov VI, Ozensoy E (2013) J Phys Chem C 117:7713-7720

17. Say Z, Vovk EI, Bukhtiyarov VI, Ozensoy E (2013) Appl Catal B 142-143:89-100

18. Say Z, Tohumeken M, Ozensoy E (2014) Catal Today 231:135-144

19. Kröcher O, Elsener M (2008) Appl Catal B 77:215-227

20. Andonova S, Vovk EI, Sjöblom J, Ozensoy E, Olsson L (2014) Appl Catal B 147:251-263

21. Kim CH, Qi G, Dahlberg K, Li W (2010) Science 327:1624-1627

22. Rousseau S, Loridant S, Delichere P, Boreave A, Deloume J, Vernoux P (2009) Appl Catal B 88:438-447

23. Li N, Boreave A, Deloume J, Gaillard F (2008) Solid State Ion 179:1396-1400

24. Royer S, Duprez D, Can F, Courtois X, Dupeyrat CB, Laassiri S, Alamdari H (2014) Chem Rev 114(20):10292-10368

25. Peña MA, Fierro JL (2001) Chem Rev 101:1981-2018

26. Rossetti I, Buchneva O, Biffi C, Rizza R (2009) Appl Catal B 89:383-390

27. Li X, Chen C, Liu C, Xian H, Guo L, Lv J, Jiang Z, Vernoux P (2013) ACS Catal 3:1071-1075

28. Zhu Y, Tan R, Feng J, Ji S, Cao L (2001) Appl Catal A 209:71-77

29. Zhang R, Alamdari H (2008) Kaliaguine. S Appl Catal A 340:140-151

30. Koponen MJ, Venalainen T, Suvanto M, Kallinen K, Kinnunen TJJ, Harkonen M, Pakkanen TA (2006) J Mol Catal A 258:246-250

31. Wang X, Qi X, Chen Z, Jiang L, Wang R, Wei K (2014) J Phys Chem C 18:13743-13751

32. Kim CH, Li W, Dahlberg KA US Patent 7, 964, 167 B2

33. Say Z, Dogac M, Vovk EI, Kalay YE, Kim CH, Li W, Ozensoy E (2014) Appl Catal B 154-155:51-61

34. Rosso I, Garrone E, Geobaldo F, Onida B, Saracco G, Specchia V (2001) Appl Catal B 34:29-41

35. Hoffman FM (1983) Surf Sci Rep 3:107-192

36. Waqif M, Bazin P, Saur O, Lavalley JC, Blanchard G, Touret O (1997) Appl Catal B 11:193-205

37. Furfori S, Russo N, Fino D, Saracco G, Specchia V (2010) Chem Eng Sci 65:120-127
38. Wang H, Zhu Y, Tan R, Yao W (2002) Catal Lett 82:199-204

39. Ammendola P, Cammisa E, Chirone R, Lisi L, Ruoppolo G (2012) Appl Catal B 113-114:11-18

40. Hung L, Bassir M, Kaliaguine S (2005) Appl Surf Sci 24:360-375

41. Crespin M, Hall WK (1981) J Catal 69:359-370

42. Dacquin JP, Dujardin C, Granger P (2008) J Catal 253:37-49

43. Bernard C, Durand B, Verelst M, Lecante P (2004) J Mater Sci 39:2821-2826

44. Ozensoy E, Min BK, Goodman DW (2004) J Phys Chem B 108:4351-4357

45. Szanyi J, Kuhn WK, Goodman DW (1993) J Vac Sci Tech 11:1969

46. Ozensoy E, Meier DC, Goodman DW (2002) J Phys Chem B 106:9367-9371

47. Ozensoy E, Goodman DW (2004) Phys Chem Chem Phys 6:3765-3778

48. Ozensoy E, Szanyi J, Peden CHF (2005) J Phys Chem B 109:3431-3436

49. Tessier D, Rakai A, Bozon-Verduraz F (1992) J Chem Soc Faraday Trans 88:741-749

50. Busca G, Lorenzelli V (1982) Mater Chem 7:89-126

51. Klingenberg B, Vannice MA (1996) Chem Mater 8:2755-2768

52. Mawdsley JR, Krause TR (2008) Appl Catal A 334:311-320

53. Haruta M, Yamada N, Kobayashi T, Iijima S (1989) J Catal 115:301-309

54. Patrito EM, Olivera PP (1998) Electrochim Acta 44:1237-1245

55. López-Suárez FE, Illán-Gómez MJ, Bueno-López A, Anderson JA (2011) Appl Catal B 104:261-267

56. Klingenberg B, Vannice MA (1999) Appl Catal B 21:19-33

57. Martinez-Arias A, Soria J, Conesa JC, Seoane XL, Arcoya A, Cataluna R (1995) J Chem Soc Faraday Trans 91:1679-1687

58. Hadjiivanov KI (2000) Catal Rev Sci Eng 42:71-144

59. Prinetto F, Ghiotti G, Nova I, Lietti L, Tronconi E, Forzatti P (2001) J Phys Chem B 105:12732-12745

60. Ghiotti G, Chiorino A (1993) Spectrochim Acta A 49:1345-1359

61. Low MJD, Yang RT (1974) J Catal 34:479-489

62. Elbouazzaoui S, Corbos EC, Courtois X, Marecot P, Duprez D (2005) Appl Catal B 61:236-243 